\title{
Governing protected areas to fulfil biodiversity conservation obligations: from Habermasian ideals to a more instrumental reality?
}

\author{
PJS Jones ${ }^{1}$
}

\begin{abstract}
:
Previously much CPR research was focused on self-governance by self-organised local actors. The focus is now shifting to the need for linkages to address the interactions amongst actors with market, state, etc structures that influence them, and on the 'scale challenges' that these interactions present. This paper considers the implications of these developments for empirical studies, with a particular focus on those concerning the governance or 'co-management' of protected areas (PAs). Two key scale challenges raised by PAs are considered: (1) the divergence of objectives between sustainable resource exploitation and biodiversity conservation; and (2) the requirement to fulfil biodiversity conservation obligations. These are explored through a UK marine PA case study which found that though even though the state had adopted a controlling role that had created tensions by undermining the authority and livelihoods of some stakeholders, the partnership had been sufficiently strengthened to withstand these tensions through the instrumental development of key links between state and civil actors: 'bracing social capital'. Four conclusions for CPR research with a particular reference to PA governance are drawn: (1) the emphasis should be on the complex dynamics of the network structure and processes in question rather than on attempting to categorise regimes or devise rules; (2) such analyses must explicitly integrate the effects of top-down institutions and interventions, recognising their positive contribution to governance; (3) the linkages at the interface between local communities and higher level state and civil institutions are particularly critical, therefore CPR analyses should be focused at this level, including analysing the potential to transfer what appears to be effective in one context to another; (4) it is important that presumptions based on Habermasian ideals do not constrain CPR analyses, in that they should constructively incorporate the strategic and instrumental roles of state and their consequences.
\end{abstract}

Key words: Scale challenges, protected area governance, bracing social capital

\section{The growing recognition of scale challenges}

It is increasingly recognised that research on CPR governance issues needs to move on from its focus on community-based case studies characterised by selforganised local actors governing the exploitation of relatively contained natural resources (Agrawal 2001; Berkes 2002, 2006; Edwards and Steins 1999; Jones and Burgess 2005; Stern et al 2002). Such research needs to recognise that linkages amongst fragmented institutions in complex governance structures go beyond local civil society (Rydin 2006) in an increasingly globalised world (Berkes 2008) and the scale challenges that these linkages present (Cash et al 2006).

\footnotetext{
${ }^{1}$ Dept of Geography, Pearson Building, UCL, Gower Street, London, WC1E 6BT, UK;

Tel +44 207679 0528; P.J.Jones@ucl.ac.uk; http://www.homepages.ucl.ac.uk/ ucfwpej/
} 
There has, however, been a long standing recognition of the challenges posed by cross-scale linkages, Dryzek (1987: 16-20, 99-100) having discussed the need for a hierarchical approach, whereby apex levels are in a position to address cross-scale linkages. He further recognises the central dilemma of environmental governance that "problems of any complexity defy such centralisation" but that decentralisation/disaggregation can undermine the integration required to accommodate such linkages (Dryzek 2005: 92-94). In order to address this dilemma he outlines a governance approach termed 'negotiated compliance' or 'rolling rule regimes' whereby central agencies set standards and compliance is negotiated locally on a 'learning by doing' adaptive management basis, with such learnings ideally being transferred through the administrative hierarchy for application in other contexts (Dryzek 2005: 95-98).

CPR researchers analyse such dilemmas on a broadly similar basis, Cash et al (2006) recognising that environmental governance outcomes are likely to be negotiated amongst actors at different scales/levels. More typically, CPR researchers discuss such dilemmas in terms of the need for horizontal and vertical linkages (Berkes 2002), Ostrom (1990) previously recognising the need for vertical linkages through 'nested' levels of appropriation, provision, enforcement and governance. Ostrom's concept further recognises that there will be different levels of decision-making, from the establishment of legal frameworks within which resource users have to operate, through to the establishment of organisational frameworks including rules for interaction between RAs and resource users, and operational frameworks including day-to-day rules controlling access to, allocation of and control over resources. There has clearly been a long standing recognition that natural resource governance must work across different institutional levels in environmental governance, including CPR, literatures.

Until recently, however, most of the empirical case studies on which CPR governance theories have been built have been purposefully selected to represent contexts where the emphasis is on self-governance by self-organised local actors, in order for the 'agency' dynamics amongst such actors in civil society to be analysed. Such research aims to identify combinations of enabling conditions that support the evolution of institutions for sustainable natural resource governance amongst local actors (Agrawal 2001). McCay (2002), on the other hand, stresses the importance of recognising that such local actors are 'embedded' in supra-individual 'structures' that operate at local and wider scales and that the influence of these structures on the evolution of governance institutions needs to be integrated into CPR studies. McCay also recognises that not only are people influenced by such structures, but that they can also influence and alter these structures. This more balanced approach that recognises the interactions between structure and agency is consistent with the theory of structuration (Giddens 1984), in keeping with which it could be argued that structure and agency institutions are inextricably intertwined and co-evolve.

So what are the implications of these developments in the theories underpinning CPR research for empirical studies? The most immediately obvious is that some of the 'critical enabling conditions' developed by CPR researchers and synthesised by Agrawal (2001) do not map well to case studies where external structural factors have a significant influence. For instance, in relation to both resource system and 
group characteristics, small size and well defined boundaries are identified as enabling conditions, but these conditions are not well met in many contexts given increasing recognition of the wide scale and dynamic nature of important ecosystem and demographics factors for resource system and group characteristics respectively. The institutional arrangement condition of locally devised access and management rules will not be well met where the state and related legal institutions have a significant role. Similarly, the external environment condition that central governments should not undermine local authority will often not be well fulfilled, whilst the condition of low levels of articulation with external markets is increasingly unlikely to be fulfilled given the growing influence of global markets. One conclusion could be that such theoretically motivated comparative case study analyses are actually very limited in terms of their transferability as they are confined to contexts where these conditions are fulfilled, but this would represent an analysis of despair.

More constructively, the increasingly common contexts where such conditions are not fulfilled can be regarded as representing 'scale challenges' (Cash et al 2006), whereby comparative case study analyses take account of contextual factors such as state policies, demographic shifts, new technologies and increasingly global markets (Agrawal 2001). The incorporation of such factors into such analyses does not preclude the quest for causal links that appear to lead to the evolution of sustainable and effective natural resource governance institutions. Whilst it increases the complexity of such analyses and raises some major methodological challenges, more importantly it also increases the validity and transferability of the findings to contexts that are becoming more common in an increasingly globalised and multilevel World.

\section{Scale challenges posed by protected area co-management}

The governance of protected areas is an important and interesting context within which to analyse scale challenges, as the findings of such research can contribute to the development both of theories and practice. An increasing proportion of the world's surface is designated as protected areas, $\sim 13 \%$ of the total terrestrial area ${ }^{2}$ and $\sim 1.5 \%$ of the total marine area under national jurisdiction ${ }^{3}$ being designated as such. At the $8^{\text {th }}$ Conference of the Parties to the Convention on Biological Diversity (2006) it was agreed that $10 \%$ of the area of all the world's habitat types should be effectively conserved through protected area designations, given that some terrestrial habitats and most marine habitats are under-represented. We are therefore likely to see a greater proportion of the world's surface area managed under protected area legislation.

For instance, in the European Union, a significant proportion of the land is subject to statutory obligations to maintain nature conservation features in a favourable condition under the Habitats Directive $(13.2 \%$ of land designated as special areas of conservation) and the Birds Directive (10.3\% of land designated as special protection areas) ${ }^{4}$. Whilst there will be some areas that have both designations, it is striking to note that as much as $20 \%$ of the terrestrial area of the EU is essentially

\footnotetext{
${ }^{2}$ http://www.unep-wcmc.org

3 http://www.fisheries.ubc.ca/publications/working/2007/2007-03.pdf

${ }^{4}$ http://ec.europa.eu/environment/nature/natura2000/barometer/index en.htm
} 
managed as protected areas, the governance of which must fulfil strategic biodiversity conservation obligations. This raises some major scale challenges that CPR analysts must engage with, given the significant proportion of the global area that is designated as protected and that such areas often cover the most productive and diverse habitats where human development and biodiversity conservation interests coincide.

Many CPR researchers have focused on the scale challenges posed by the governance of protected areas, e.g. Berkes (2004), Jones and Burgess (2005), Mascia (2003), Pretty and Smith (2006). In a more applied policy context, recognition has grown over the last two decades that local people affected by protected areas should be involved in their planning and management to increase the fairness of decisions and promote local ownership and cooperation. This key aspect of the new paradigm for protected areas was recognised at the IUCN's 5th World Parks Congress (Phillips 2003). The term 'collaborative management' (hereafter referred to as 'co-management') describes a range of approaches to provide for the participation of different actors in protected area management. It is recognised as a "broad concept spanning a variety of ways by which the agency in charge and other stakeholders develop and implement a management partnership" (BorriniFeyerabend 1999, 228).

There has been a tendency in some quarters, e.g. Murphree (1994), for comanagement to be considered as synonymous with community-based management, whereby the emphasis is on empowering local people in protected areas through reinforcing their proprietorship of these areas, which the intervention of the 'agency in charge' is considered to undermine (Geisler 2002). Such approaches are a response to the recognition of the 'risks of imposition', such as alienation, apathy and defiance amongst local people whose rights are displaced through the designation as 'protected' of the area in which they undertake their activities (Jones and Burgess 2005) that is a key driver for the emerging dominance of the co-management paradigm. However, in recent years there have been a growing number of papers that question the view that 'the more community-based protected area management is, the better'. These focus on what might be termed the 'risks of parochialism' (Jones and Burgess 2005), such as that biodiversity conservation objectives will be undermined by local resource exploitation objectives (McClanahan 2004, Saunders 2008, Walters 2004) and that local inequities amongst people affected by protected area designations will be reinforced (Lane and Corbett 2005, Ostrom 1999).

Against this background Berkes (2002) notes that "the balance of evidence from the commons literature of the past few decades is that neither purely local-level management nor purely higher level management works well by itself". The challenge, then, is to achieve an appropriate balance between top-down and bottomup approaches (Jones and Burgess 2005), or what Cash et al. (2006) refer to as the 'middle path' approach, leading to a more progressive definition of co-management: "power-sharing in the exercise of resource management between a government agency and a community or organization of stakeholders" (Pinkerton, 1992). The challenges raised by sharing power in protected area co-management are being addressed amongst research, e.g. Adger et al. (2006), Young (2006), and policy, e.g. Borrini-Feyerabend et al. (2004), communities but this remains an under-researched area (Adger et al 2006). 
There are two key and inter-related scale challenges that are posed by protected area governance:-

- The divergence of objectives between sustainable resource exploitation and biodiversity conservation: accepting that resource exploitation objectives will, at best, be focused on sustainability, basic conflicts will be generated in protected area governance due to the emphasis of the state on biodiversity conservation objectives where most local users are focused on (sustainable) resource exploitation (Jones 2001). The majority of CPR case studies are focused on sustainable resource exploitation objectives so the divergence of objectives and the related value pluralities can present particular CAPs for protected area governance institutions.

- The requirement to fulfil biodiversity conservation obligations to higher statutory authorities, given which the state arguably cannot shift from being a controller to a facilitator, which it has been argued is necessary for successful governance (Ostrom 1990), as the state has a duty to ensure the fulfilment of these obligations, so must maintain an element of control. This also means that the enabling conditions of locally devised access and management rules and central governments should not undermine local authority will be challenging to fulfil or they may be considered to be inappropriate (Jones and Burgess 2005).

The extreme challenges of devising vertically linked institutions to implement international agreements on global biodiversity are highlighted by Stern et al (2002) as a priority for further research, particularly linkages below the nation-state level to meet management objectives set internationally, recognising that there are different objectives at different levels. However, to date very few CPR governance case studies focus on protected areas and even fewer, if any, explicitly take account of these two key challenges. Given the significant and growing proportion of the land and sea that is designated as protected area it is argued that analyses of related governance issues through case studies that take specific account of these two key challenges is a critical priority.

A key issue for such analyses will be the potential of different institutional designs to establish power relations through vertically and horizontally linked and nested institutions that can provide for a balance to be achieved between local resource exploitation and biodiversity conservation. This is arguably a critical issue for the comanagement of protected areas in general. If this balance cannot be achieved, the potential of co-management to fulfil strategic biodiversity conservation obligation may be critically undermined.

\section{Scale challenges posed by marine protected area co-management}

The co-management of marine protected areas (MPAs) poses several particular challenges from a CPR governance perspective and my associates and I focus on empirical research on the scale challenges posed by MPAs (Jones and Burgess 2005). Jones (2001) argues for a 'middle ground' approach which balances local and national perspectives and concerns, whilst Kelleher (1999) stresses that the design 
and management of MPAs must be both top-down and bottom-up, but what do these statements mean in the complex realities that any given MPA represents? Roberts and Jones (in press) address this question, building on Jones and Burgess (2005), through a case study of an MPA on the NE coast of England: the Wash \& North Norfolk Coast European Marine Site $\left(\mathrm{EMS}^{5}\right)$. A key premise of this research is that the 'statutory partnership' model under which EMSs are managed might be considered as an oxymoron, in that the statutory obligations and powers remain with the state therefore the asymmetrical distribution of power precludes a partnership where stakes, responsibilities and powers are shared between local users and the state.

This research was focused on a public inquiry that had upheld the refusal of the conservation agency to grant mussel cultivators permission to scare eider ducks that feed on cultivated mussels off their lays using sonic bird-scaring devices The research found that this statutory intervention by the state, in order to ensure the fulfilment of conservation obligations, had created tensions between local resource exploitation and strategic conservation objectives and their had been a break down of trust between some stakeholders and state representatives. Fortunately, however, the extent and degree of the tensions was limited and the partnership was strong enough to resist fracturing or even collapse. Subsequent research has found that the partnership has actually been strengthened by other factors, particularly the official recognition that the mudflats of the EMS were recovering from the previous overexploitation of shellfish and the coincidence of this with a combination of high shellfish prices, high shellfish catches and the discovery of local sources of mussel spat for the cultivators. Furthermore, the conservation agency and the fishing community, of which the mussel cultivators are a part, have become united in opposition to a major wind farm proposal on the Wash estuary.

\section{Bracing social capital as a means of addressing scale challenges}

This case study supports arguments that co-management through a state-civil society partnership can be effective in overcoming significant collective action problems, even though statutory interventions by the state necessary to fulfil imposed biodiversity conservation obligations undermined the authority of some actors and the partnership has an asymmetrical distribution of power. As well as the emerging external factors related to high shellfish catches/prices and the shared threat posed by the wind farm proposal, our research indicates that 'bracing social capital' developed through the Wash EMS partnership was a key factor in enabling it to address the CAPs faced.

Bracing social capital is "a kind of social scaffolding" that is "primarily concerned to strengthen links across and between scales and sectors but only operates within a limited set of actors". It is driven by the increasing need for partnerships to deliver on policy goals, therefore bracing social capital is developed through strategic, selective, focused and instrumental processes, and its development is often guided by the state in order to reinforce partnerships in such a way that they can fulfil specific

\footnotetext{
${ }^{5}$ European Marine Site (EMS) is the UK term for SACs and SPAs that include intertidal and subtidal areas and are subject to the previously discussed obligations under the Habitats and Birds Directives.
} 
policy obligations (Rydin and Holman 2004). Rydin (2006) discusses how bracing social capital is a concept that considers the horizontal and vertical linkages between the state and civil society that go beyond the locality and are necessary to achieve strategic policy objectives that are increasingly prevalent in natural resource governance contexts. As such, bracing social capital is analogous to what Jones and Burgess (2005) discuss in terms of 'partnership capacity'. In the context of this paper bracing social capital is a key means of addressing the scale challenges, or what Saglie (2006) refers to as the 'problems of institutional fragmentation', posed, for example, by protected area governance.

\section{Conclusions:}

\section{The implications of addressing scale challenges for CPR governance research}

Given the increasing recognition that CPR governance analyses need to move beyond focusing on the institutional interactions amongst local civil society actors, what are the implications for research related to, for instance, the governance of protected areas?

Firstly, it is argued that the emphasis of analyses should be on the complex dynamics of the network structure and processes in question, through which different powers are expressed in different ways, rather than on attempting to categorise regimes or devise rules. There is a tendency amongst CPR analysts to attempt to categorise cases in a way that does not reflect their complexity and dynamism. For example, Young (2006) outlines a typology of 'interplay patterns' but it is argued that few, if any, networks represent static regimes which can be categorised using schemes such as this as they are likely to display a combination of interplays at different times in different contexts.

The responses to scale challenges outlined by Cash et al. (2006) also tend towards being too categorical, in that the three categories of responses essentially represent different elements of most natural resource governance networks. Whilst they recognise that CPR governance models can involve an integration of all three responses, it is argued that the response 'institutional interplay' describes the vertical and horizontal linkages and the processes that occur across them, and 'boundary or bridging organisations' describes the actors that facilitate these linking processes, 'co-management' being the name given to the sum of these processes. Rather than being separate categories of responses, they actually represent the processes, nodes and whole network respectively.

Similarly, it is argued that there is increasingly little to be gained from employing context specific 'critical enabling conditions' or developing ever more complicated sets of such conditions to encompass contexts characterised by scale challenges. Whilst we should continue to strive to identify combinations of causal links that appear to lead to the evolution of sustainable and effective natural resource governance institutions in a given context, the focus should be on more 'middle range' theories such as social capital and institutional capacity (Rydin 2006), rather than on developing more theoretically abstract categorisation schemes and normative systems of critical enabling conditions. 
The emphasis should be on observing and analysing the dynamics of processes and structures in a given case study, recognising that they represent components of hierarchical complex adaptive systems, and then seeking elements that appear to be successful in addressing CAPs raised by scale challenges, such as bracing social capital and other incentive structures/processes, which can be adapted and applied in similar case study contexts. This represents an argument to go back to a more basic institutional analysis approach rather than developing more theoretically and normatively abstract approaches in our quest to address the complexities of scale challenges.

Secondly, accepting the importance of higher levels of organisation and regulatory frameworks for providing monitoring, assessment, and enforcement, and fostering local management at a community level (Berkes 2006, Rydin 2006), protected area and related CPR governance analyses must explicitly integrate the effects of topdown institutions and interventions, recognising their positive contribution to governance. A level of particular importance and interest in this respect is the interface between local communities and higher level state and civil institutions, and it is argued that the concept of bracing social capital is a particularly useful means of analysing the linkages at this critical interface that appear to be key to the development of resilient and effective natural resource governance institutions.

Thirdly, it is argued that if the linkages at the interface between local communities and higher level state and civil institutions are accepted as critical, CPR analyses that seek approaches that appear to be successful in addressing CAPs raised by scale challenges should be focused at this level, including analysing the potential to transfer what appears to be effective in one context to another. As such, it is argued that addressing scale challenges is as much about 'transferring across' as it is about 'scaling up'.

Fourthly and finally, it is argued that whilst special issues of journals such as those introduced by Cash et al (2006) and Berkes (2008) are focused on integrating the scale challenges associated with an increasingly multi-level World into CPR analyses, many CPR analyses are still implicitly or explicitly influenced by Habermasian ideals of communicative rationality (Habermas 1984). Such analyses are thus premised on assumptions such as that the facilitation of rational deliberations amongst local actors unencumbered by imposed agendas can be effective in developing norms, etc that lead to sustainable CPR governance regimes. Many of the critical enabling conditions synthesised by Agrawal (2001) reflect such assumptions. As CPR analysts become more focused on addressing scale challenges, however, including explicit recognition of the potential positive contributions of top-down institutions and interventions, it is important that presumptions based on Habermasian ideals do not constrain CPR analyses.

It must be recognised that the state has important roles to play in CPR governance and that these roles will often be more instrumental and, to a degree, controlling in nature, in order to ensure the fulfilment of obligations to legal institutions such as the Habitats/Birds Directives and the Convention on Biological Diversity, as well as related obligations to wider society and future generations. CPR analyses will be limited in their potential to address scale challenges if this recognition is undermined by Habermasian ideals. For example, Steins and Edwards (1999) argue that 
negotiations amongst actors on CPR platforms are obstructed if strategic narratives are adopted. However, state representatives are bound to strategically participate in such discussions in order to ensure that their statutory obligations are fulfilled. Buck (1999) accordingly stresses that the institutional imperatives of the state should be incorporated into CPR analyses whilst Jones and Burgess (2005) discuss the need for the state to sometimes 'temper' its facilitation role. Such initiatives to incorporate the role of the state into CPR analyses, including a sometimes controlling role, will be undermined by the implicit or explicit adherence to Habermasian ideals.

Adherence to such ideals would certainly preclude, for instance, the search for strategic and instrumental processes that are often guided by the state in order to reinforce partnerships through bracing social capital in such a way that desired policy goals can be fulfilled (Rydin 2006).

It is therefore important that CPR case study analyses are focused on addressing scale challenges, including through the sometimes controlling role of the state, as such roles represent both important forces for the evolution of sustainable and effective natural resource governance institutions and important elements of such institutions. From Hobbes to Hardin to Habermas and back again... towards a coevolutionary synthesis that more explicitly addresses scale challenges?

\section{References}

Adger, W.N., K. Brown and E.L. Tompkins. 2006. The political economy of crossscale networks in resource co-management. Ecology and Society 10(2): 9. www.ecologyandsociety.org/vol10/iss2/art9.

Agrawal, A. 2001. Common property institutions and sustainable governance of resources. World Development 29(10): 1649-1672

Berkes, F. 2002. Cross-scale institutional linkages: perspectives from the bottom up. 293-321 in E. Ostrom, T. Dietz, N. Dolšak, P.C. Stern, S. Sonich and E.U. Weber (Eds) The Drama of the Commons. Washington, DC: National Academy Press.

Berkes, F. 2004. Rethinking community-based conservation. Conservation Biology 18(3): 621-630.

Berkes, F. 2006. From community-based resource management to complex systems: the scale issue and marine commons. Ecology and Society 11(1): 45. www.ecologyandsociety.org/vol11/iss1/art45/.

Berkes, F. 2008. Commons in a multi-level World. International Journal of the Commons 2(1): 1-6.

Borrini-Feyerabend, G. 1999. Collaborative management of protected areas. 225234 in S. Stolton and N. Dudley (Eds) Partnerships for Protection: new strategies for planning and management for protected areas. London: Earthscan. 
Borrini-Feyerabend, G., M. Pimbert, M.T. Farvar, A. Kothari and Y. Renard. 2004. Sharing Power: a global guide to collaborative management of natural resources. London: Earthscan.

Buck, S.J. 1999. Multiple-use commons, collective action, and platforms for resource use negotiation. Agriculture and Human Values 16(3), 237-239.

Cash, D.W., W.N. Adger, F. Berkes, P. Garden, L. Lebel, P. Olsson, L. Pritchard and O. Young. 2006. Scale and cross-scale dynamics: governance and information in a multi-level World. Ecology and Society 11(2): 8.

www.ecologyandsociety.org/vol11/iss2/art8/.

Dryzek, J.S. 1987. Rational ecology: environment and political economy. New York: Basil Blackwell.

Dryzek, J.S. 2005. The politics of the Earth: environmental discourses. Second Edition. Oxford: OUP.

Edwards, V.M. and N.A. Steins. 1999. Special issue introduction: the importance of context in common pool resource research. Journal of Environmental Policy \& Planning 1(3), 195-204.

Geisler, C. 2002. Murphree's Law. The Common Property Resource Digest 60, 4 (http://www.indiana.edu/ iascp/E-CPR/cpr60.pdf)

Giddens, A. 1984. The Constitution of Society: Outline of the theory of structuration. Berkeley: University of California Press.

Habermas, J. 1984. The theory of communicative action; Volume 1: Reason and the Rationalization of Society. Boston: Beacon Press.

Jones, P.J.S. 2001. Marine protected area strategies: issues, divergences and the search for middle ground. Reviews in Fish Biology and Fisheries 11(3), 197-216.

Jones P.J.S. and J. Burgess. 2005. Building partnership capacity for the collaborative management of marine protected areas in the UK: a preliminary analysis. Journal of Environmental Management 77(3), 227-243

Kelleher, G. 1999. Guidelines for marine protected areas. Gland: IUCN.

Lane M.B. and T. Corbett. 2005. The tyranny of localism: indigenous participation in community-based environmental management. Journal of Environmental Policy \& Planning 7(2), 141-159.

McCay, B.J. 2002. Emergence of institutions for the commons: contexts, situations and events. In Ostrom, E., Dietz, T., Dolšak, N., Stern, P.C., Stonich, S and Weber, E. The Drama of the Commons. National Academy Press. Washington. DC. 
Mascia, M. 2003. The human dimension of coral reef marine protected areas: recent social science research and its policy implications. Conservation Biology 17(2), 630632.

McClanahan T. 2004. The limits to beyond boundaries. Aquatic Conservation: Marine and Freshwater Ecosystems 14, 1-4.

Murphree M.W. 1994. The role of institutions in community-based conservation. 403427 in D. Western, R.M. Wright and S.C. Strum (Eds) Natural Connections: perspectives in community-based conservation. Washington DC: Island Press.

Ostrom, E. 1990. Governing the commons: the evolution of institutions for collective action. Cambridge: Cambridge University Press.

Ostrom, E. 1999. Coping with Tragedies of The Commons. Annual Review Political Science 2, 493-535.

Pinkerton, E.W. 1992. Translating legal rights into management practice: overcoming barriers to the exercise of co-management. Human Organization 51(4), 330-341.

Phillips, A. 2003. Turning ideas on their head: the new paradigm for protected areas. George Wright Forum 20(2), 8-32. www.georgewright.org/202phillips.pdf

Pretty, J. and D. Smith. 2006. Social capital in biodiversity conservation and management. Conservation Biology 18(3), 631-638.

Roberts, T. and P.J.S. Jones. In press. Shellfishing, eider ducks and nature conservation on the Wash: questions raised by a fractured partnership. Society and Natural Resources.

Rydin, Y. 2006. Institutions and networks: the search for conceptual research tools. 15-33 in Rydin, Y. and E. Falleth. (Eds) 2006. Networks and institutions in natural resource management. Cheltenham, UK: Edward Elgar Publishing.

Rydin, R. and N. Holman. 2004. Re-evaluating the contribution of social capital in achieving sustainable development. Local Environment 9(2): 117-133.

Saglie, I. 2006. Fragmented institutions: the problem facing natural resource management. 1-14 in Rydin, Y. and E. Falleth. (Eds) 2006. Networks and institutions in natural resource management. Cheltenham, UK: Edward Elgar Publishing.

Saunders $\mathrm{F}$ et al. 2008. An examination of governance arrangements at Kisakasaka Mangrove Reserve in Zanzibar. Environmental Management 41, 663-675.

Steins, N.A. and V.M. Edwards. 1999. Synthesis: platforms for collective action in multiple-use common-pool resources. Agriculture and Human Values 16(3), 309315.

Stern, P.C., Dietz, T., Dolšak, N., Ostrom, E. and Stonich, S. 2002. Knowledge and questions after 15 years of research. 445-489 in E. Ostrom, T. Dietz, N. Dolšak, P.C. 
Stern, S. Sonich and E.U. Weber (Eds) The Drama of the Commons. Washington, DC: National Academy Press.

Walters, B.B. 2004. Local management of mangrove forests in the Philippines: successful conservation or efficient resource exploitation? Human Ecology 32(2), 177-195.

Young, O. 2006. Vertical interplay among scale-dependent environmental and resource regimes. Ecology and Society 11(1): 27.

www.ecologyandsociety.org/vol11/iss2/art27/. 